\title{
Using Case Studies to Promote Group Learning and Teamwork Skills
}

\author{
Oscar Nespoli \\ University of Waterloo \\ oscar@uwaterloo.ca \\ William Owen \\ University of Waterloo \\ bowen@uwaterloo.ca \\ Stephan Lambert \\ University of Waterloo \\ steve@uwaterloo.ca
}

\begin{abstract}
Waterloo Cases in Design Engineering (WCDE) has been established to enhance engineering design education by developing case studies from student cooperative work term reports, and implementing them across the entire Faculty of Engineering. One design case, developed from a student report, was used in three (3) different courses during one academic term as a precursor activity to a class or term design project. The results of a student survey indicate that the design case was an engaging application and that group discussion and interaction helped to enhance students' understanding of the design method, and the specific design challenge described in the case. Instructor perspectives are summarized on using design cases and the case method with students in teams to develop teamwork and other complementary abilities.
\end{abstract}

\section{Introduction}

The University of Waterloo (UW) is a co-operative engineering school where students are required to obtain practical engineering experience between each academic term. Over 4000 work term reports capturing this experience are submitted for academic credit each year. Waterloo Cases in Design Engineering (WCDE) has been established to enhance design engineering education by developing some of these reports into design cases, and implementing them across the entire Faculty of Engineering.
Cases and the case method have been used extensively and successfully in business, law, medicine and engineering to capture and deliver accounts of real situations and experiences for use in a classroom setting [1]. Business education practices usually require that students use cases in individual study, group study and then classroom discussion in order to best impart learning for the student [2]. These progressively integrated social activities and interactions are intended to enhance individual learning and promote individual understanding as the explicit educational goal. While it is recognized that group learning can foster communication and teamwork skills, students are ultimately assessed individually, for their proposed management actions while in the shoes of the protagonist. In engineering education using cases, an opportunity exists to have both individual and team learning as explicit educational goals, and assess both individual and team-based performance.

All stakeholders who hold an interest in engineering education; students, faculty, university administration, industry, government, accreditation bodies and especially the general public, recognize that a portion of engineering education requires that students demonstrate so called non-technical, soft or higherorder skills and abilities, and that these skills be well integrated with demonstrated competencies in mathematics, natural sciences and engineering fundamentals. 
The Canadian Engineering Accreditation Board (CEAB), following the changes introduced by Applied Science Accreditation Commission (ABET) in the United States of America (USA), specify graduate attributes and program criteria that includes such skills and abilities [3]. The new CEAB criteria and procedures indicate that the institution must demonstrate that graduates of a program possess abilities in design, problem analysis, investigation, use of engineering tools, individual and teamwork, communication, professionalism, impact of society and the environment, ethics and equity, economics and project management and life long learning.

In addition, there have been a number of reports and initiatives summarizing the challenges facing the engineering profession and engineering educators over the years, among them the recognition of the need to develop the global engineer [4],[5],[6],[7]. The profession of engineering 'has a new global significance - and responsibilities' demanding students be aware and develop an appreciation for the impact their work can have in a global context.

Cases offer a proven mechanism to address this educational opportunity. Cases can bring examples of real situations into the classroom, providing the crucial contextual information that is often lacking with problems assigned from the textbook. An opportunity exists to use cases to provide a consistent and harmonized way to simulate practice thereby integrating important fundamental knowledge taught in lecture settings with skills and abilities learned during workshops, laboratory and design project settings. The importance of such settings to develop problem solving skills and teamwork has been known for some time [8].

The value of teams in industry is undeniable. It is the fundamental unit creating value for an enterprise through a design and innovation activity. Engineering students must develop the procedural knowledge and skills to design and the skills necessary to function efficiently and effectively on teams, both as members and leaders. There are challenges when working in teams, but as [9] confirms, the 'challenges are the benefits'. There is learning that takes place during a group or team exercise. Coupling cases with teambased learning, or co-operative learning [10], [11], can provide real, open-ended, context rich challenges where student teams can learn technical and nontechnical skills expected of them by industry and society prior to graduation.
The design case developed and implemented in this study shows promise in addressing many of the new educational challenges, and seems to show particular promise for group learning and teamwork skill development.

\section{Design Case Development}

The design case used for the group learning and teaming activity was developed from a $4^{\text {th }}$ year student capstone project report [12]. The case is an account of how the student author suffered a knee injury during a soccer match. The injury severed the peroneal nerve, which is located within the knee joint. This resulted in a condition called foot drop. The long term consequence of this condition is that the author could not lift or evert (twist outward) his foot, making walking difficult and running impractical. The case captures the design challenge of returning the author to an active lifestyle of running by designing, fabricating and evaluating a novel foot brace design. The case is structured in modules, a so-called interrupted case, to reflect the stages in the engineering design process. Each module represents a stage in the process, Table 1.

\begin{tabular}{|c|l|}
\hline Module No. & \multicolumn{1}{|c|}{ Title } \\
\hline-01 & $\begin{array}{l}\text { Foot Brace for Long Distance } \\
\text { Running - Case Introduction }\end{array}$ \\
\hline-02 & $\begin{array}{l}\text { Need Analysis and Problem } \\
\text { Formulation }\end{array}$ \\
\hline-03 & Conceptual Design \\
\hline-04 & Preliminary Design \\
\hline-05 & Prototype Fabrication \\
\hline- TN & Teaching Note \\
\hline
\end{tabular}

Table 1 - WCDE-00023 Case Modules

A teaching note was also developed, in order to provide a recommended implementation method to instructors intending to use the case [13]. The teaching note includes an introduction describing the case, teaching objectives and intended learning outcomes, a description of the central design challenge facing the protagonist, recommended case implementation method and a request that the instructor provide formal feedback on the case and their chosen implementation method.

The implementation recommended included having students work in groups and to have them reflect on the design task (case module) provided between each module. It was intended that the students move through Kolb's learning cycle [14], beginning with 
Concrete Experience (CE), followed by Reflective observation (RO). Group activities varied slightly with each implementation as described below.

\section{Design Case Implementation}

The design case was implemented in three (3) courses over the same academic term; ME380 Mechanical Engineering Design Workshop; ME423 Mechanical Design 2; ME729 Design Methods.

\subsection{ME380 Case Implementation Method}

ME380, Mechanical Engineering Design Workshop, is a third year core course and it is intended to teach and reinforce the engineering design process through the design, fabrication and evaluation of a physical artefact. Students must work in teams throughout the process. The students group themselves into teams of five based on individual skill requirements of leadership (planning and management), design analysis (simulations, design calculations, material selection, drafting), and hands-on (procurement, tools, construction, machine shop). The breakdown was one leader, two individuals with design analysis skills, and two with hands-on skills. The mechanical devices are tested on a competition day, where marks are assigned for design quality and performance.

This case study was implemented prior to the design and build of the mechanical device, over a several week period early in the term to promote learning of the design process. Student teams were required to read the case (-01) and were then required to do a needs assessment and problem formulation as an assignment, all on their own time. A short report of 25 pages was submitted the following week which was then followed by a short classroom discussion. In addition to handing in a group report, each individual had to hand in their own rough work to show participation. This also served to demonstrate that a majority of the teams were able to divide responsibilities amongst team members and then synthesis a single report from the team. This implementation method was then repeated for the next three (3) of the remaining four (4) modules of the case.

The case was well received by this group of students and did serve its purpose to aid in learning the design process. Three major criticisms from the students were the workload, the open-endedness to the case study, and the size of the teams, some felt that five team members was not easily managed.
The workload was heavier than anticipated, partly due to the students desire to generate high quality work; they put a lot of extra effort in just to gain a few extra marks. The design problem in the case study was somewhat open ended, giving the students some leeway in formulating the problem. This approach is reflective of what they will experience after graduation, but not what they are used to in academia where most problems are well defined and are looking for a specific outcome.

A few groups felt that five member teams were too large; communication and organizing meetings were difficult and sometime personality conflicts came into play. That, however, is a part of the challenge in working in teams.

\subsection{ME423 Case Implementation Method}

ME423 Mechanical Design 2 is a $4^{\text {th }}$ year elective course focusing on machine design and machine elements, and includes a major design project component as part of the course. The design project scope is less than that of ME380, but requires students to work in teams to design and verify a mechanical power transmission device.

The case was used as a precursor to the design project, to remind them of the design process. The case was delivered as the teaching note recommended, with students in teams during class. Only the case (-01) the need analysis (-02) and the conceptual design (-03) modules were given in class as the teaching objective was to remind them of the importance of problem definition and conceptual design thinking.

Student teams had already been formed for a hardware dissection exercise; they were asked to self direct themselves into teams and select appropriate roles within the teams. The class of 24 students assembled into five (5) teams. The literature reports advantages and disadvantages to this method of assigning students to teams, however in the end all teams were very successful in generating very good designs for the term project, and without any required instructor intervention to resolve personnel issues [15].

After a short introductory lecture on the design process, students were assigned the case as a reading for the next week's lecture.

Most students did not read the case, and so they were asked to assemble into teams in class and read and discuss the case as a group for 20 minutes. They were then asked to perform a need analysis and to articulate 
the real need, a list of functional design requirements, constraints and decision criteria, and to generate a preliminary list of design specifications that would describe the design challenge. Each group was required to present their own work in front of the class. The classroom discussion was facilitated by the instructor, and there was very good interaction between students and between instructor and students.

The process was repeated for the conceptual design phase in the following week. The final solution to the case was presented later in the term, to allow the other two (2) course implementations to be completed without influence from the ME423 students. A class discussion was again facilitated by the instructor, where the novelty and appropriateness of the solution was discussed, and the project management techniques used to generate and evaluate a successful prototype were highlighted and emphasized.

There was very good after class informal feedback from several students. They indicated how they enjoyed doing the case and that they felt it was important to relate their formal training to real life examples.

\subsection{ME729 Case Implementation Method}

ME729 Design Methods is a relatively new graduate course and is part of a new Master of Engineering Design Certificate program. It attracts working professionals and foreign trained students who are interested in upgrading their engineering design skills. A major class project is part of this course offering as well but the focus was on the conceptual design stage for a novel application, to encourage thorough problem definition for ill-defined problems. In this case, students were asked to design a fixture to hold a glass vase during carving for a local artist.

This class was relatively small, 17 students, and the discussion of the case was performed before the class was further sub-divided into smaller teams to solve the major design project. The case was used to provide an overview of the design process, with special emphasis on the problem definition phase. Therefore only the case (-01) and the need assessment (-02) was delivered.

\section{Survey Method}

Based on earlier experiences delivering and assessing the benefits of cases [16], a survey was developed in order to capture students' feedback. Although the survey was general in nature, a significant objective was to obtain feedback on whether group and classroom discussions helped their learning and understanding. 43 of 91 students available responded to the surveys, for a response rate of $47 \%$. Further details of the survey method and questions can be found in a recent publication [17].

\section{Observations and Results}

The first survey question was intended to assess the students' understanding of the learning objective of the case. The teaching objectives were not listed and the student was asked to determine the teaching objective. The results are shown in Figure 1.

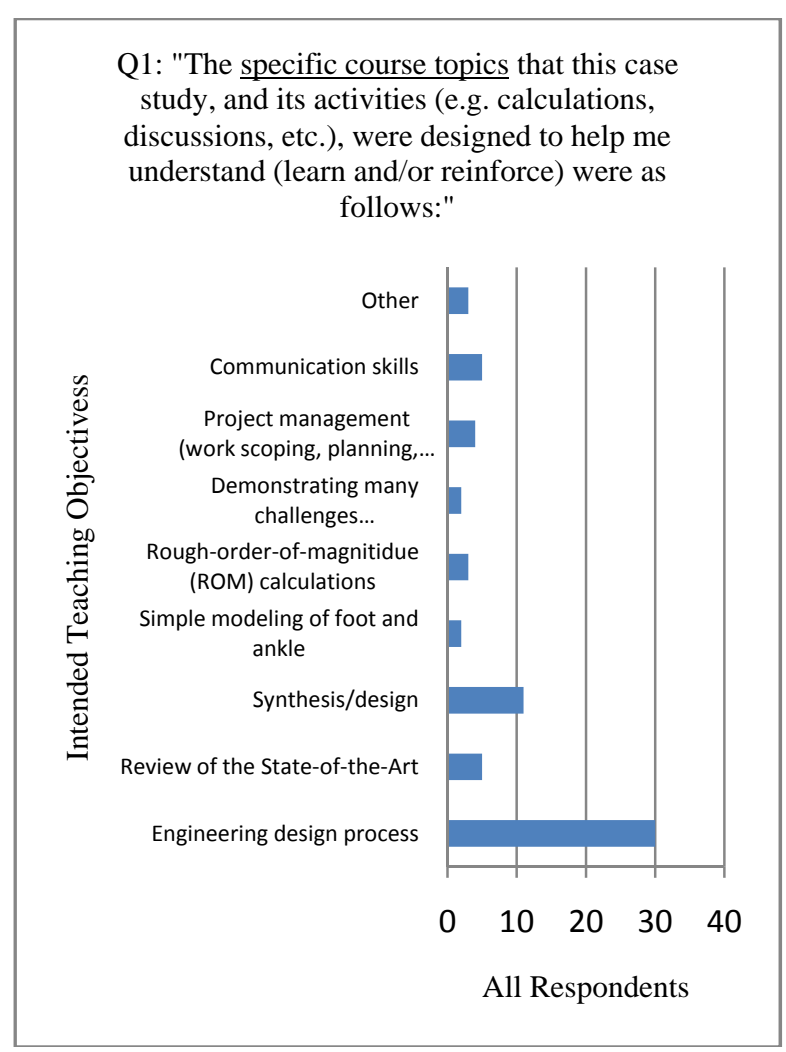

Figure 1 - Survey Question 1 Results

The students' responses indicated that they understood that the case was designed to promote their understanding of the design method as the primary teaching objective.

The following figures present results of a number of respondents according to a five (5) point agreement scale. The bars moving from left to right correspond to: ME380, ME423, ME729 and All results, respectively. Results are shown as percentages for all 
results only with actual numbers corresponding in brackets beside the percentage labels.

Question 2 of the survey was intended to gauge students' interest and engagement with the case as a learning method. $84 \%$ of students found the case to be an engaging application of the engineering design process.

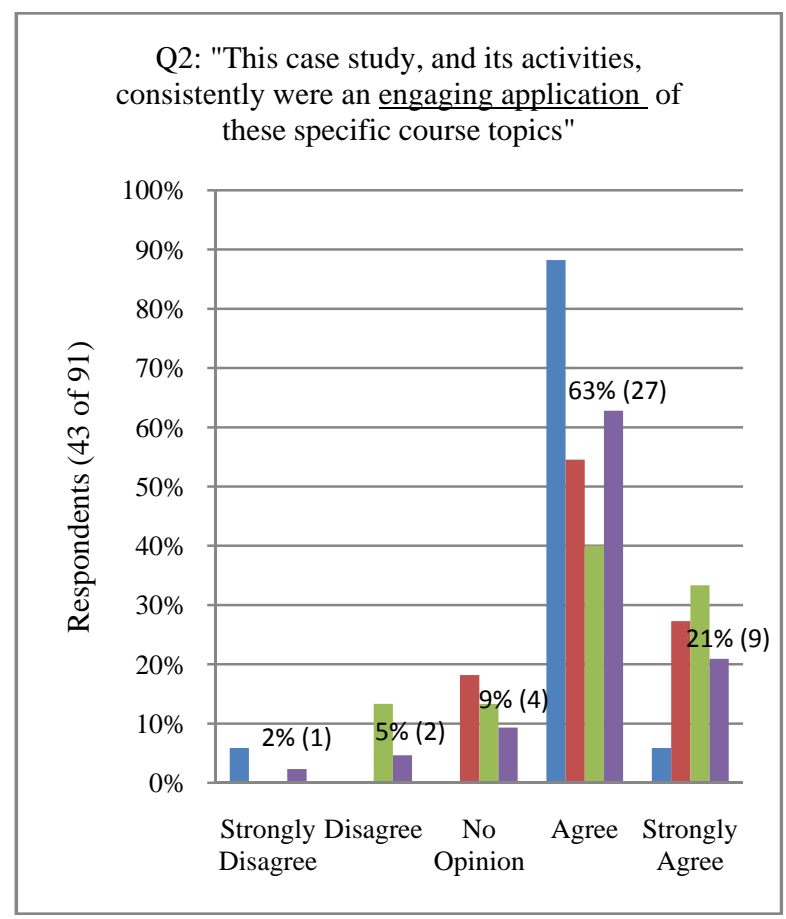

Figure 2 - Survey Question 2 Results

When asked whether the case improved the students' appreciation of the relevance of the engineering method on the course topics being studied, fully $79 \%$ agreed or strongly agreed.

Fully $75 \%$ of students agreed or strongly agreed that the case helped them understand the specific course topics being taught. There was some variance in the data for ME423, and it is thought that this was due to the fact that the case did not feature machine elements such as gears, bearings, clutches and/or brakes.

One of the most revealing questions asked whether group discussions helped students' understand the specific course topic - the engineering design process. As Figure 3 indicates, over $80 \%$ of respondents agreed or strongly agreed with this statement. This suggests that communication within the group was indeed taking place, and that it was useful in helping student understand. This suggests that learning happens in groups, [9] goes on to suggest that this learning occurs in organizations, and that the major benefits include the development of project management skills, developing a broad perspective, teaming skills, expanding one's social network (especially important in an organization) and boundary-spanning skills. It is further suggested that the struggles encountered in integrating the expertise and in facing the challenges together in an uncertain endeavour build capabilities for learning and collaboration.

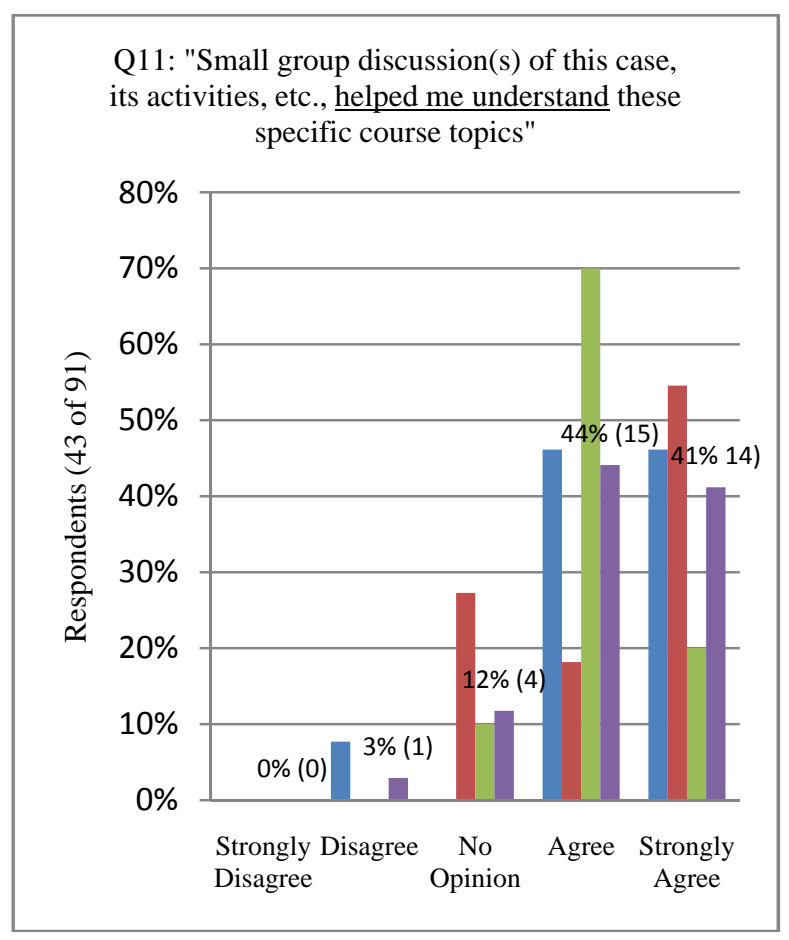

Figure 3 - Survey Question 11 Results

Fully $82 \%$ of students agreed or strongly agreed that classroom discussions were also very important in helping them understand the specific course topic. This always followed the individual reading and group discussion in all three (3) case implementations. This is an interesting corollary to the notion that learning takes place in groups. It appears that student's also found that the discussion in class was useful in solidifying their understanding as well.

Eight (8) of 16 students (not all respondents answered this question) disliked that the workload was high for the case study, and one (1) student reporting that they disliked group work. We have observed that students have difficulty internalizing the concept of work scope and work planning. We believe that there is an opportunity to improve their understanding of the significance of this concept for design projects. 
Of 26 student respondents, seven (7) suggested that the work load be reduced or that the scope of the case be better defined. This result is not entirely surprising, since it is this very skill that open-ended cases and projects offer as a learning opportunity. Four (4) students recommended that the case be done during class time, also corroborating this above observation of a lack of appreciation for the learning opportunity for time and work management.

Question 16 asked the students to identify the advantages of the case study. Eleven (11) students recognized the importance of it being a real example, four (4) reporting that learning of design was an advantage and three (3) of the 23 respondents indicated that active learning was important.

\section{Future Research}

Domains of learning have been expressed as comprising of cognitive (knowledge), affective (attitude) and psychomotor (skills) dimensions [18]. Most efforts in individual teaching and learning are focussed on the cognitive dimension. There has been a recognition of the importance of developing individual learning in both cognitive and affective dimensions, with one program explicitly designing a portion of the curriculum to address this [8].

Our interest is in testing the validity of these learning models to team-based learning, and using the case method as the research methodology. The University of Waterloo will have a unique opportunity to develop expertise here, as the new Engineering V Student Design Centre will be completed within the next year and will house all of the student design teams. This facility will offer the setting required to research and develop methods for learning about and enhancing team-based learning.

\section{Conclusions}

The results of this study are encouraging for our program. The students reported that the case was an engaging application that helped them to understand the learning objectives. They functioned in teams during the implementation and reported that group discussions helped them to understand the learning objectives. The teams that completed the case went on to function as effective teams for follow-on class projects in each of the courses taught.
The students in all courses demonstrated, through completion of group assignments and presentations, that they could design, investigate problems and solve them, use engineering tools, communicate amongst themselves and with instructors, appreciate the importance of project management tools and techniques to some degree, and finally, for this specific case, appreciate that engineering design can have a beneficial impact on the lifestyle of an injured person.

\section{References}

[1] N. J. Delatte Jr., Beyond Failure: Forensic Case Studies for Civil Engineers, American Society for Civil Engineers (ASCE), 2008.

[2] L.A Mauffette-Leenders, J.A. Erskine and M.R. Leenders, Learning with Cases, Richard Ivey School of Business, University of Western Ontario, 2005.

[3] Engineers Canada, Accreditation Criteria and Procedures 2008, September 2008.

[4] A.D.C. Chan and J. Fishbein, “A Global Engineer for the Global Community”, The Journal of Policy Engagement, Vol. 1, No. 2, May 2009.

[5] K.A. Smith, Teamwork and Project Management, McGraw-Hill, 2004.

[6] S.D. Sheppard, K. Macatangay, A. Colby and W.M. Sullivan, Educating Engineers: Designing for the Future of the Field, Jossey-Bass, 2009.

[7] The CDIO Initiative, www.cdio.org, accessed July $2^{\text {nd }}, 2009$.

[8] D.R. Woods et al, "Developing Problem Solving Skills: The McMaster Problem Solving Program”, Journal of Engineering Education, April 1997.

[9] A.C. Edmondson and I.M. Nembhard, "Product Development and Learning in Project Teams: The Challenges are the Benefits”, Journal of Product Innovation Management, Volume 26, pp. 123-138, March 2009.

[10] P.T. Terenzini et al, “Collaborative Learning versus Lecture/Discussion: Students’ Reported Learning Gains”, Journal of Engineering Education, January 2001. 
[11] R.M. Felder and R. Brent, "Designing and Teaching Courses to Satisfy the ABET Engineering Criteria”, Journal of Engineering Education, January 2003.

[12] D. Bishop and O. Nespoli, "Foot Brace Design for Long Distance Running”, WCDE-00023, Waterloo Cases in Design Engineering (WCDE), 2008.

[13] O. Nespoli, "Foot Brace for Long Distance Running - Teaching Note”, WCDE-00023-TN, Waterloo Cases in Design Engineering (WCDE), 2008.

[14] D.A. Kolb, Experiential Learning: Experience as the Source of Learning and Development, Englewood Cliffs, NJ: Prentice-Hall Inc., 1984

[15] E. Lumsdaine, J. Loukes, J. Dreyer, S. Chenoweth and M. Lumsdaine, "Forming and Managing Project Teams in a Large Capstone Design Course”, ASEE 2009 Conference Proceedings, June 2009.

[16] C. Campbell and S. Lambert, "Using Case Studies to Teach Introductory Design Concepts to First Year Engineers, ASEE 2007 Conference

Proceedings, June 2007.

[17] O. Nespoli, W. Owen and S. Lambert, "Engineering Case Study Implementation: Observations, Results and Perspectives", ASEE Conference Proceedings, June 2009.

[18] Centre for Teaching Excellence (CTE), University of Waterloo, 2008. 